\title{
Pengembangan Kedai Rumah Madinah Dalam Menentukan Strategi Bersaing
}

\author{
Charles Yosep ${ }^{1}$, Rahayu Puji Suci ${ }^{2}$, Dharmayanti Pri Handini ${ }^{3}$
}

\begin{abstract}
Abstrak
Penelitian ini merumuskan strategi bersaing yang dapat digunakan Kedai Rumah Madinah Malang dimasa yang akan datang dengan menggunakan metode Matriks IFAS, Matriks EFAS, Matriks SWOT, Matriks I-E, Matriks SWOT dan Matriks QSPM. Metode kuantitatif pendekatan deskriptif. Setting penelitian di Kedai Rumah Makan Madinah Malang.

Hasil penelitian menunjukkan bahwa kemampuan Kedai Rumah Makan Madinah Malang dengan IFAS dan EFAS mampu menutupi kelemahannya. Pada tahap pengambilan keputusan dengan QSPM, alternatif strategi yang terpilih adalah Market Development Strategy (pengembangan pasar) pada Kedai Rumah Makan Madinah Malang. Strategi ini memiliki skor $T A S$ yang sebesar 6.595.

Keterbatasan/Implikasi pada penelitian adalah perlu meningkatkan Peningkatan promosi dengan memanfaatkan teknologi yang ada melalui media masa seperti: instagram, facebook, Google.
\end{abstract}

Kata Kunci: Strategi,IFAS,EFAS,SWOT,I-E,QSPM.

\begin{abstract}
This research formulates a competitive strategy that can be used in the Rumah Rumah Madinah Malang in the future using the IFAS Matrix, EFAS Matrix, SWOT Matrix, I-E Matrix, SWOT Matrix and QSPM Matrix. Quantitative method. Research settings at the Madinah Malang Restaurant.

The results showed that the ability of Malang Medina Restaurant Shops with IFAS and EFAS were able to exploit their weaknesses. At the decision making stage with QSPM, the alternative strategy chosen was the Market Development Strategy at the Madinah Malang Restaurant Shop. This strategy has a TAS score of 6,595.

Limitations / Implications for research need to increase Promotion by utilizing existing technology through mass media such as: Instagram, Facebook, Google.
\end{abstract}

Keywords: Strategy, IFAS, EFAS, SWOT, I-E, QSPM.

\footnotetext{
${ }^{1}$ Fakultas Ekonomi, Universitas Widyagama, Malang, charlesronaldo95@gmail.com

${ }^{2}$ Fakultas Ekonomi, Universitas Widyagama, Malang

${ }^{3}$ Fakultas Ekonomi, Universitas Widyagama, Malang
} 


\section{PENDAHULUAN}

Berwirausaha merupakan salah satu kunci dari berbisnis. Hal tersebut dapat diketahui dari membangun strategi agar dapat bersaing dengan kompetitor-kompetitor lainnya. Sehingga dapat menguasai (market share) yang ada. Bisnis berhasil jika menerapkan perencanaan bisnis yang matang. Proses penyusunan strategi sangat dibutuhkan, karena merupakan perencanaan jangka panjang.

Kedai Rumah Madinah Malang adalah salah satu usaha yang bergerak di bidang kuliner memiliki pengunjung dan omset penjualan yang meningkat karena tidak lepas dari perencanaan strategi bersaing. Pada saat ini strategi yang digunakan di Kedai Rumah Madinah yaitu strategi biaya rendah dimana harga menu makanannya terbilang murah dan terjangkau (10 ribu -15 ribu) terutama dikalangan mahasiswa. Kedai Rumah Madinah Malang dapat menggunakan cost leadership, differentiation, dan focus (Porter (1997; 1998) untuk dapat bersaing dengan kompetitor lainnya. Kedai Rumah Madinah Malang ini letaknya sangat strategis dimana berdekatan dengan kawasan perumahan dan kost-kostan mahasiswa, yang biasanya berlangganan di Kedai Rumah Madinah Malang ini.

Beberapa masalah juga dihadapi Kedai Rumah Madinah Malang diantaranya: belum punya SOP (Standar Operasional Prosedur) bagi karyawan, sehingga karyawan khususnya bagi pelayan agar tidak bingung dalam melakukan pekerjaannya dan hanya fokus pada divisinya dan tidak mencampuri ke divisi yang lainnya, misal pelayanan hanya melayani pelanggan dan tidak mencampuri divisi dapur. Hal tersebut berdampak terhadap pelayanan yang kurang maksimal, karena para karyawan bingung dalam tugasnya, banyaknya pelanggan yang komplain mengenai pelayanan dan cita rasa makanan yang disajikan. Seperti lambatnya pesanan disajikan kepada para pelanggan dan cita rasa makanan yang disajikan berbeda-beda dari hari ke hari. Hal ini disebabkan karena faktor internal seperti yang telah dijelaskan dalam permasalahan pertama dan kokinya tidak mempunyai standar cita rasa yang tepat, dan belum mempunyai Job Description sehingga karyawannya bingung dengan tugas dan tanggung jawabnya serta tidak fokus pada pekerjaan yang seharusya di kerjakan, dengan adanya Job Description karyawan bisa mengetahui sistematis tentang tugas, wewenang dan tanggung jawab suatu jabatan/bagian tertentu, dapat menjelaskan dan berfokus pada pekerjaan itu sendiri dan bukan kepada personil yang mengisi pekerjaan tersebut. Job description ini sangat penting, terutama untuk menghindarkan terjadinya perbedaan pengertian sehingga dapat menghindari pekerjaan rangkap, serta untuk mengetahui batas-batas tanggung jawab dan wewenang masing-masing jabatan/bagian, Banyaknya pengunjung yang datang ke Kedai Rumah Madinah Malang tidak untuk memesan makanan atau minuman tetapi semata-mata hanya untuk memanfaatkan wifi saja, Kurangnya promosi sehingga jumlah pelanggan yang berkunjung tidak stabil dari bulan ke bulan, dan Kedai Rumah Madinah Malang juga memiliki beberapa pesaing sejenis yang ada di kota Malang.

\section{KAJIAN PUSTAKA}

\section{Strategi Bersaing}

Strategi bersaing adalah pencarian akan posisi bersaing yang menguntungkan dalam suatu industri, arena fundamental tempat persaingan terjadi. Strategi bersaing dirumuskan untuk meningkatkan daya saing perusahaan di mata pelanggan maupun calon pelanggan. Strategi bersaing akan memberikan keunggulan terhadap perusahaan itu sendiri sehingga akan membedakan perusahaan tersebut dengan perusahaan lainnya. 


\section{B ulletin of \\ $\mathbf{M}$ anagement \& \\ B usiness}

ISSN-p:

ISSN-e:

DOI:

Hal seperti inilah yang akan menumbhkan persaingan yang sehat dengan pelanggan yang telah tersegmentasi (Porter, 1993).

\section{METODE PENELITIAN}

Penelitian ini merupakan penelitian kuantitatif dengan pendekatan deskriptif. Setting penelitian di Kedai Rumah Madinah Malang. Pengumpulan data berasal dari jumlah pengunjung Kedai Rumah Madinah 2018-2019 dan data yang berasal dari luar organisasi / perusahaan / instansi itu sendiri. Analisis penelitian ini diantaranya menggunakan Analisis IFAS (Internal Factors Analysis Summary), Analisis Faktor Eksternal (EFAS), Matriks IE (Internal-Eksternal), Matriks SWOT, dan Quantitive Strategic Planning Matrix (QSPM).

\section{HASIL DAN PEMBAHASAN}

Dari hasil identifikasi lingkungan dirumusakan faktor kekuatan, kelemahan, peluang dan ancaman yang dihadapi Kedai Rumah Madinah Malang diantaranya:

Tabel 1 Analisis Lingkungan Analisis Lingkungan

\begin{tabular}{|c|c|c|}
\hline & Kekuatan & Kelemahan \\
\hline $\begin{array}{l}\text { Faktor } \\
\text { Internal }\end{array}$ & $\begin{array}{l}\text { Produk yang ditawarkan bervariasi } \\
\text { yang menyajikan makanan Indonesia } \\
\text { - Harga makanan relatif murah dimana } \\
\text { harga per porsinya Rp } 10 \text { ribu - Rp15 } \\
\text { ribu } \\
\text { - Pelayanan yang ramah dan baik } \\
\text { - Promosi yang dilakukan efektif dan } \\
\text { efisien via sosial media (Instagram, } \\
\text { facebook dan Google) } \\
\text { - Bahan baku yang digunakan segar } \\
\text { - Bahan baku yang digunakan halal }\end{array}$ & $\begin{array}{l}\text { Tenaga ahli yang terbatas (chef) ( } 2 \\
\text { orang ) } \\
\text { - } \quad \text { Cita rasa makanan yang selalu } \\
\text { berubah-ubah } \\
\text { - } \quad \text { Belum mempunyai pedoman atau } \\
\text { acuan untuk melaksanakan tugas } \\
\text { atau perkerjaan sesuai dengan } \\
\text { fungsinya / Standar Operasional } \\
\text { Prosedur (SOP) } \\
\text { - Tempatnya kurang luas yang hanya } \\
\text { terdiri kurang dari } 10 \text { meja saja } \\
\text { - Desain tempat kurang menarik } \\
\text { - Lahan parkir masih sempit } \\
\text { Kecepatan pelayanan kurang } \\
\text { maksimal }\end{array}$ \\
\hline
\end{tabular}




\begin{tabular}{|c|c|c|}
\hline \multicolumn{3}{|c|}{ Analisis Lingkungan } \\
\hline & Peluang & Ancaman \\
\hline $\begin{array}{l}\text { Faktor } \\
\text { Eksternal }\end{array}$ & 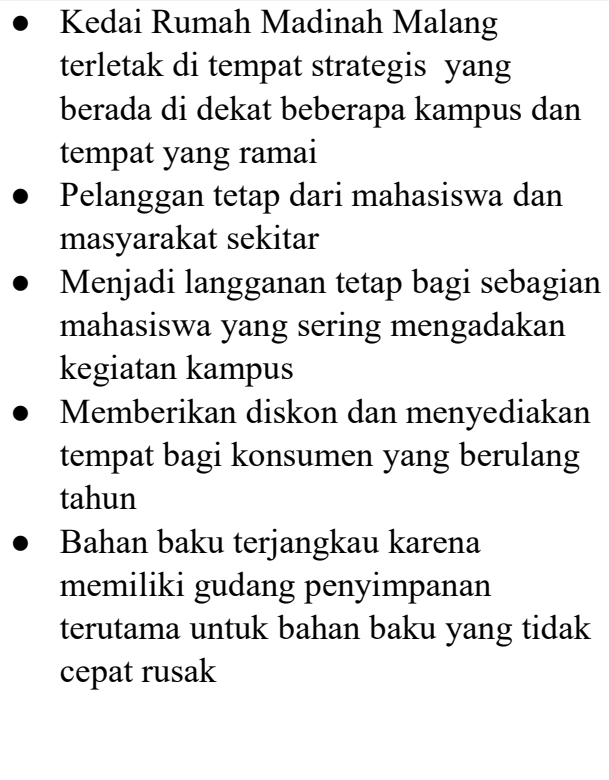 & $\begin{array}{l}\text { - Teknologi, perkembangan teknologi } \\
\text { memberikan ancaman kepada Kedai } \\
\text { - Rumah Madinah Malang hal ini } \\
\text { dikarenakan rata-rata konsumen memilih } \\
\text { tempat makan sesuai dengan } \\
\text { kepopuleran tempat tersebut di dunia } \\
\text { maya } \\
\text { - Harga yang ditawarkan kompetitor } \\
\text { Kedai Rumah Madinah Malang } \\
\text { cenderung bervariasi dan lebih banyak } \\
\text { yang murah } \\
\text { - Selera masyarakat yang cepat berubah } \\
\text { dapat menyebabkan kemunduran apabila } \\
\text { tidak melakukan inovasi-inovasi baru } \\
\text { - Persaingan yang ketat karena banyaknya } \\
\text { rumah makan yang menyajikan makanan } \\
\text { yang sejenis } \\
\text { Bahan baku mengalami kenaikan harga }\end{array}$ \\
\hline
\end{tabular}

\section{Tahap Input Stage (Masukan)}

Hasil analisis dan identifikasi kondisi lingkungan internal yang berupa kekuatan dan kelemahan disusun dalam matriks IFAS sedangkan analisis lingkungan eksternal yang berupa peluang dan ancaman disusun dalam matriks EFAS.

Total skor dari hasil IFAS sebesar 3,04 dari skor rata-rata 2,5 yang mengindikasikan bahwa Kedai Rumah Madinah Malang memiliki posisi internal yang kuat untuk mengatasi kelemahan yang ada. Kekuatan utama yang dimiliki Kedai Rumah Madinah Malang dengan skor yang sama 0,32 yaitu harga makanan relatif murah dimana harga per porsinya $\mathrm{Rp} 10$ ribu - Rp15 ribu dan produk yang ditawarkan bervariasi yang menyajikan makanan Indonesia. Selanjutnya kekuatan Kedai Rumah Madinah Malang yang mempunyai skor yang sama 0,24 yaitu bahan baku yang digunakan masih segar, bahan baku yang digunakan halal, pelayanan yang ramah dan baik, promosi yang dilakukan efektif dan efisien via sosial media (Instagram, facebook dan Google) dan bahan baku terjangkau karena memiliki gudang penyimpanan terutama untuk bahan baku yang tidak cepat rusak dan Memberikan diskon dan menyediakan tempat bagi konsumen yang berulang tahun.

Kelemahan yang dimiliki oleh Kedai Rumah Madinah Malang yang berada pada posisi pertama yang yang mempunyai skor yang sama 0,12 yaitu belum mempunyai pedoman atau acuan untuk melaksanakan tugas atau perkerjaan sesuai dengan fungsinya / Standar Operasional Prosedur (SOP), desain tempat kurang menarik, lahan parkir masih sempit dan tempatnya kurang luas yang hanya terdiri kurang dari 10 meja saj2a. Kelemahan kedua yang ada pada Kedai Rumah Madinah Malang dengan skor yang sama 0,16 adalah tenaga ahli yang terbatas (chef), cita rasa makanan yang selalu berubah-ubah dan kecepatan pelayanan kurang maksimal. 


\section{B ulletin of

Berdasarkan total skor EFAS sebesar 2.80 dari skor rata-rata 2,5 yang mengindikasikan bahwa Kedai Rumah Madinah Malang memiliki posisi eksternal yang kuat dalam memanfaatkan/merespon peluang untuk mengatasi ancaman yang ada dari luar Kedai Rumah Madinah Malang. Peluang utama yang dimiliki oleh Kedai Rumah Madinah Malang dengan skor yang sama 0,48 adalah Kedai Rumah Madinah Malang terletak di tempat strategis yang berada di dekat beberapa kampus dan tempat yang ramai, Kerja sama dengan pemasok/supplier (bahan baku) dan Perkembangan Teknologi dan Komunikasi dapat digunakan sebagai sarana untuk mempromosikan Kedai Rumah Madinah Malang seperti melakukan kerja sama dengan gojek dan grab. Menempati urutan kedua, yaitu Pelanggan tetap dari mahasiswa dan masyarakat sekitar dengan skor 0.36. Selanjutnya yang terakhir adalah Menjadi langganan tetap bagi sebagian mahasiswa yang sering mengadakan kegiatan kampus dengan skor 0,30. Sedangkan, ancaman utama dengan skor yang sama 0,10 yaitu Teknologi, perkembangan teknologi memberikan ancaman kepada Kedai Rumah Madinah Malang hal ini dikarenakan rata-rata konsumen memilih tempat makan sesuai dengan kepopuleran tempat tersebut di dunia maya dan Harga yang ditawarkan kompetitor Kedai Rumah Madinah Malang cenderung bervariasi dan lebih banyak yang murah.

Diurutan kedua dengan skor yang sama 0,16 adalah Selera masyarakat yang cepat berubah dapat menyebabkan kemunduran apabila tidak melakukan inovasi-inovasi baru dan Bahan baku mengalami kenaikan harga. Selanjutnya ancaman yang terakhir yaitu Persaingan yang ketat karena banyaknya rumah makan yang menyajikan makanan yang sejenis dengan skor 0,18 .

\section{Tahap Matching Stage (Pencocokan)}

\section{Analisis Matriks Internal dan Eksternal (I-E)}

Matriks I-E dihasilkan melalui penggabungan informasi yang diperoleh dari matriks IFAS dan EFAS untuk mendapatkan informasi mengenai posisi perusahaan guna mempermudah dalam pemberian alternatif strategis. Nilai matriks EFAS sebesar 2,80 menunjukkan Kedai Rumah Madinah Malang memiliki kemampuan tiggi dalam memanfaatkan peluang dan menghindari ancaman yang ada. Sedangkan nilai matriks IFAS sebesar 3,04 menunjukkan Kedai Rumah Madinah Malang memiliki faktor internal yang tergolong tinggi dalam memanfaatkan kekuatan yang dimiliki untuk mengatasi kelemahan internal yang ada dimana Kedai Rumah Madinah Malang berada pada pada sel IV Strategi tumbuh dan bina (Growth and Build) yang. Strategi yang tepat untuk diterapkan adalah strategi intensif (penetrasi pasar, pengembangan pasar dan pengembangan produk). a, Penetrasi Pasar berfokus pada penjualan produk-produk yang ada di pasar-pasar yang ada sebelumnya, contohnya berfokus pada makanan khas Indonesia (ayam rica, ayam merah, sate usus, tempe bacem, tahu, dan lain-lain), b. Pengembangan pasar adalah merebut pangsa pasar yang lebih besar dari pangsa pasar saat ini dan mengembangkan pasar baru bagi produk yang ada saat ini. Contohnya, membuka cabang baru ditempat yang baru dengan menjual produk yang ada, c, pengembangan produk berfokus pada pengembangan produk baru untuk pasar yang telah ada saat ini dan mengembangkan produk baru untuk pasar baru. Contohnya, menciptakan produk baru atau menjual produk makanan barat seperti, steak, burger,spaghetti,macaroni,kebab, dan lain-lain. 


\section{B ulletin of \\ $\mathbf{M}$ anagement \& \\ B usiness}

ISSN-p:

ISSN-e:

DOI:

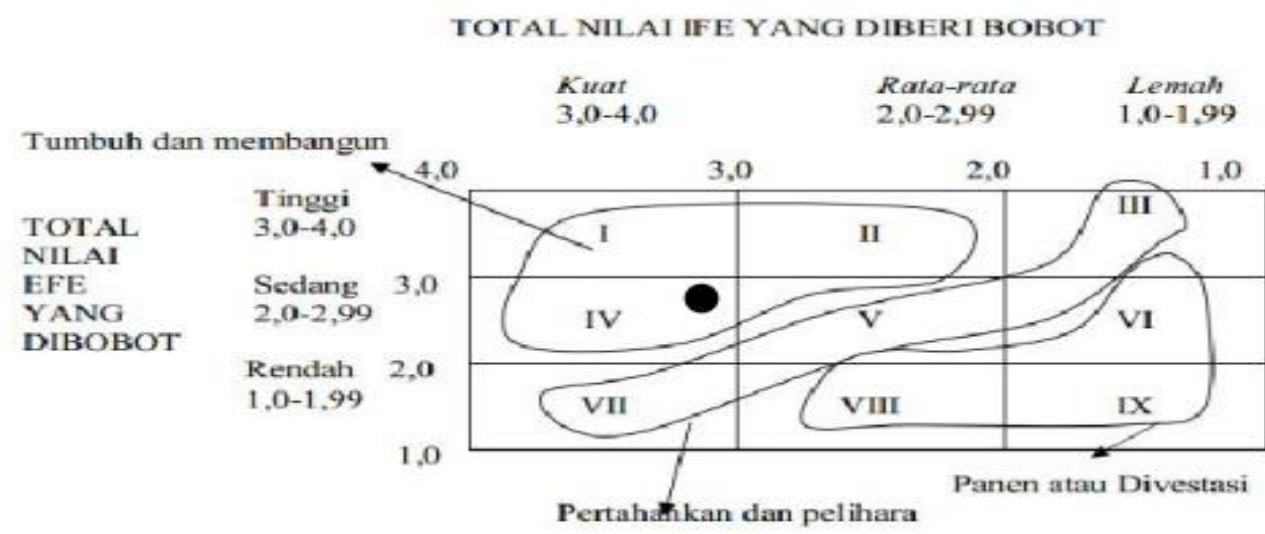

Keterangan :

Posisi Kedai Rumah Madinah Malang

Sumber : Data Primer diolah, 2019

Gambar 1 Matriks I-E Kedai Rumah Madinah Malang

\section{Analisi Matriks SWOT}

Tabel 2 Analisis Matriks SWOT Kedai Rumah Madinah Malang

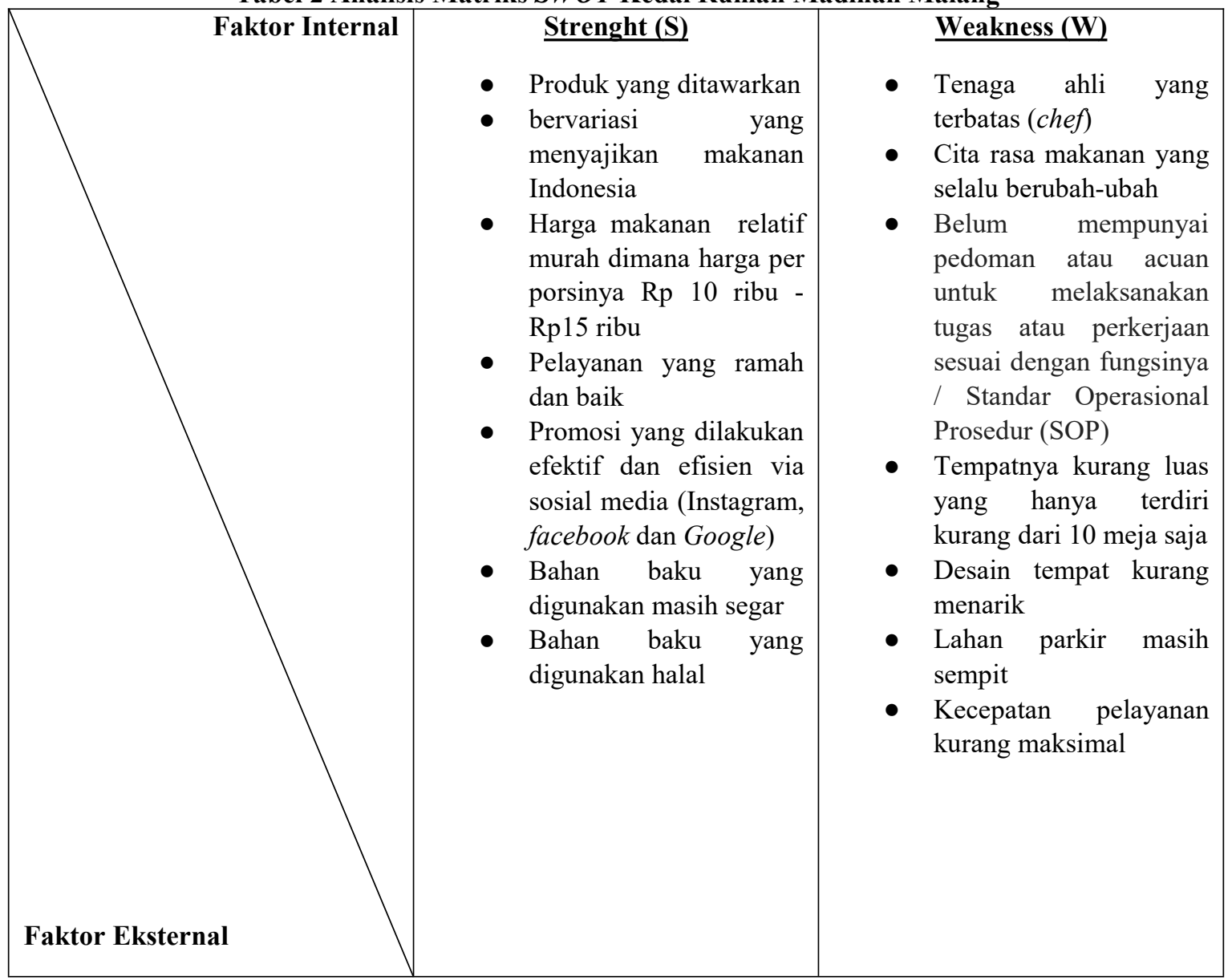



B ulletin of
M anagement \&
ISSN-p:
B usiness
ISSN-e:
DOI:

Lanjutan Tabel 2

\begin{tabular}{|c|c|c|}
\hline $\begin{array}{l}\text { OPPORTUNITY (O) } \\
\text { - Kedai Rumah Madinah Malang } \\
\text { terletak di tempat strategis yang } \\
\text { berada di dekat beberapa kampus } \\
\text { dan tempat yang ramai } \\
\text { - Pelanggan tetap dari mahasiswa } \\
\text { dan masyarakat sekitar } \\
\text { Menjadi langganan tetap bagi } \\
\text { sebagian mahasiswa yang sering } \\
\text { mengadakan kegiatan kampus } \\
\text { Memberikan diskon dan } \\
\text { menyediakan tempat bagi } \\
\text { konsumen yang berulang tahun } \\
\text { Bahan baku terjangkau karena } \\
\text { memiliki gudang penyimpanan } \\
\text { terutama untuk bahan baku yang } \\
\text { tidak cepat rusak }\end{array}$ & $\begin{array}{ll} & \text { STRATEGIS-O} \\
\text { - } & \text { Meningkatkan } \\
& \text { jumlah konsumen } \\
\text { - } & \text { Meningkatkan } \\
\text { strategi pemasaran } & \\
\text { dengan } \\
\text { memaksimalkan } \\
\text { promosike } \\
\text { masyarakat Malang }\end{array}$ & $\begin{array}{l}\text { STRATEGI W-O } \\
\text { - } \\
\text { Peningkatan } \\
\text { sarana dan } \\
\text { prasarana } \\
\text { - Peningkatan } \\
\text { kualitas SDM } \\
\text { denganmemberik } \\
\text { an pelatihan skill } \\
\text { serta } \\
\text { memberikan } \\
\text { sosialisasi } \\
\text { kepada karyawan }\end{array}$ \\
\hline 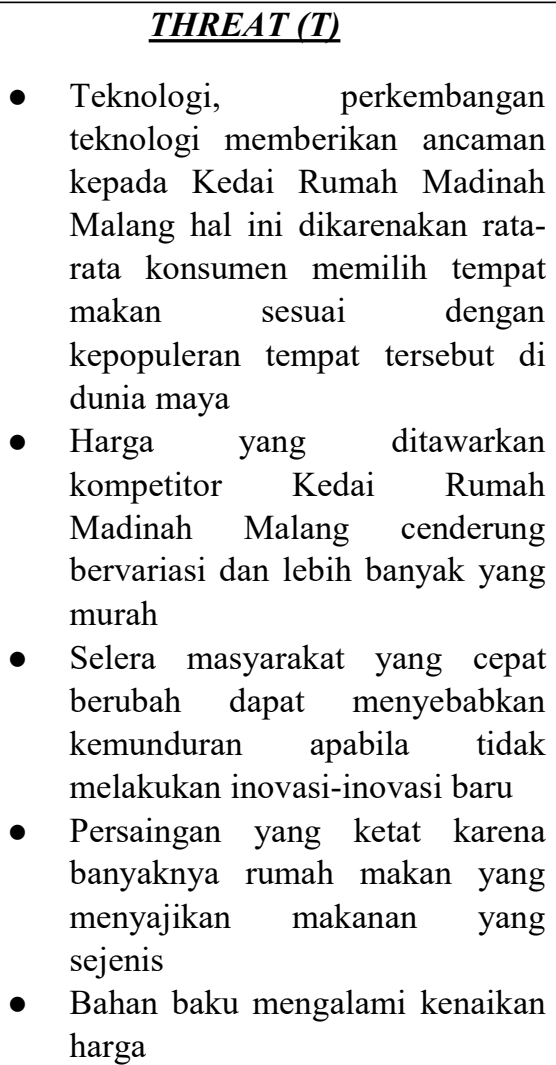 & $\begin{array}{ll}\text { STRATEGI S-T } \\
\text { - } \\
\text { Peningkatan promosi } \\
\text { dengan } \\
\text { memanfaatkan } \\
\text { teknologi yang ada } \\
\text { - } \text { Mempertahankan } \\
\text { kualitas dan harga } \\
\text { menu makan pada } \\
\text { Kedai Rumah } \\
\text { Madinah Malang }\end{array}$ & $\begin{array}{ll}\text { STRATEGI } \boldsymbol{W} \text { - } \\
\text { - } & \text { Peningkatan } \\
& \text { sarana dan } \\
& \text { prasarana } \\
\text { - } & \text { Peningkatan } \\
\text { pelayanan } \\
\text { kepada } \\
\text { konsumen }\end{array}$ \\
\hline
\end{tabular}

\section{Tahap Decision Stage (Keputusan)}

Tahap terakhir dari analisis strategi merupakan pemilihan strategi yang sesuai dan dapat dijalankan oleh instansi. Pemilihan strategi yang cocok dilakukan dengan menggunakan analisis QSPM. Alternatif strategi didapatkan dari matriks SWOT dimana matriks tersebut menghasilkan alternatif strategi melalui faktor internal dan eksternal instansi. 
Keputusan matriks QSPM merupakan alat analisis yang digunakan untuk pengambilan keputusan strategi. Pengambilan keputusan yang dilakukan berdasarkan pada alternatif strategi berdasarkan matriks IE dan matriks SWOT. Alternatif strategi terpilih adalah:

1. Product Development Strategy

2. Market Development Strategy

3. Market Penetration Strategy

4. Brand Image Strategy

Berdasarkan hasil dari perhitungan menggunakan analisis QSPM didapatkan alternatif strategi utama yang memiliki nilai TAS tertinggi yaitu Market Development Strategy dengan nilai 6,595. Strategi ini dilakukan dengan cara meningkatkan jumlah konsumen dan meningkatkan strategi pemasaran dengan memaksimalkan promosi ke masyarakat Malang.

Strategi dengan prioritas kedua yaitu Market Penetration Strategy dengan skor 6,565 , strategi ini dilakukan dengan cara peningkatan sarana dan prasarana dan peningkatan kualitas SDM dengan memberikan pelatihan skill serta memberikan sosialisasi kepada karyawan. Strategi proritas ketiga yaitu Product Development Strategy dengan nilai sebesar 6,111 dilakukan dengan cara peningkatan promosi dengan memanfaatkan teknologi yang ada dan mempertahankan kualitas dan harga menu makan pada Kedai Rumah Madinah Malang. Alternatif strategi terakhir yaitu Brand Image Strategy dengan skor sebesar 6,11. Strategi ini dilakukan dengan cara peningkatan sarana dan prasana serta peningkatan pelayanan kepada konsumen.

\section{KESIMPULAN DAN SARAN}

Berdasarkan uraian-uraian hasil dan pembahasan diatas, mengenai perencanaan pengembangan strategi bersaing pada kedai rumah madinah disimpulkan bahwa analisis akhir menggunakan qspm (quantitative strategy planning matrix) menghasilkan strategi market development strategy (strategi pengembangan pasar). strategi ini dilakukan dengan cara meningkatkan penjualan produk yang sudah ada.

Dalam mengembangkan usahanya, Kedai Rumah Madinah Malang harus mengatasi kelemahan internalnya. Kelemahan yang ada yaitu tenaga ahli yang terbatas (chef), cita rasa makanan yang selalu berubah-ubah, belum mempunyai pedoman atau acuan untuk melaksanakan tugas atau perkerjaan sesuai dengan fungsinya / Standar Operasional Prosedur (SOP), tempatnya kurang luas yang hanya terdiri kurang dari 10 meja saja, desain tempat kurang menarik, lahan parkir masih sempit, kecepatan pelayanan kurang maksimal. Serta perlu meningkatkan Peningkatan promosi dengan memanfaatkan teknologi yang ada melalui media masa seperti: instagram, facebook, Google dan lain-lain, sehingga lebih banyak lagi masyarakat yang mengetahui keberadaan Kedai Rumah Madinah Malang ini.

\section{REFERENSI}

Amalia, Syarah dan Mahendra Fakhri. 2016. Pengaruh Motivasi Kerja terhadap Kinerja Karyawan pada PT. Gramedia Asri Media Cabang Emerald Bintaro. Jurnal Computech \& Bisnis, Vol. 10, No 2, Hal: 119-127.

Berry L.M. and Houston, J.P. 2013. Psychology at Work: An Introduction to. Industrial and Organizational Psychology. New York; McGraw-Hill. 
Brahmansari dan Paniel Siregar. 2009. Pengaruh Budaya Organisasi, Kepemimpinan Situasional dan Pola Komunikasi terhadap Disiplin Kerja dan Kinerja Karyawan pada PT Central Proteina prima Tbk. Jurnal Aplikasi Manajemen. 7 (1), Februari 2009.

Budi, Setiyawan dan Waridin. 2006. Pengaruh Disiplin Kerja Karyawan dan Budaya Organisasi Terhadap Kinerja di Divisi Radiologi RSUP Dokter Kariadi, Semarang. Jurnal Riset Bisnis Indonesia (JRBI). Vol 2. No 2. Hal: 181-198.

Hakim, Abdul. 2006. Analisis Pengaruh Motivasi, Komitmen Organisasi dan Iklim Organisasi Terhadap Kinerja Pegawai Pada Dinas Perhubungan dan Telekomunikasi Provinsi Jawa Tengah. Jurnal Riset Bisnis Indonesia (JRBI). Vol 2. No 2. Hal: 165-180.

Hasibuan, Malayu S.P. 2007. Manajemen Sumber Daya Manusia Perusahaan. Bandung: Bumi Aksa.

Hofstede, Geert, Gert Jan Hofstede, dan Michael Minkov. 2010. Cultures and Organizations. 3rd edition. New York: Mc GrawHill.

Kreitner, Robert dan Angelo Kinicki. 2005. Perilaku Organisasi (Orgaizational Behavior). Jakarta: Salemba Empat.

Mangkunegara, A.A. Anwar Prabu. 2011. Manajemen Sumber Daya Manusia Perusahaan. Bandung: Remaja Rosda Karya.

Marina, Lina. 2011. Pengaruh Karakteristik Pekerjaan terhadap Motivasi Kerja Salesman PT. Bentoel Prima Wilayah Pemasaran Surabaya. Skripsi. Fakultas Psychology, Universitas Airlangga.

Mathis, R.L. \& J.H. Jackson. 2006. Human Resource Management: Manajemen Sumber Daya Manusia. Terjemahan Dian Angelia. Jakarta: Salemba Empat.

Moses, Rendi Mahardika. 2014. Pengaruh Karakteristik Individu dan Karakteristik Pekerjaan terhadap Prestasi Kerja Karyawan (Penelitian pada Karyawan PT Inti Bara Mandiri Tuban). Jurnal Administrasi Bisnis. Vol. 12 No. 1, Hal: 1-5.

Munandar, Ashar Sunyoto. 2008. Psikologi Industri dan Organisasi. Jakarta: UI-Press.

Panudju, Agung. 2003. Pengaruh Kompensasi dan Karakteristik Pekerjaan terhadap Kepuasan Kerja Karyawan Unit Produksi PT. X Palembang. Jurnal Manajemen \& Bisnis Sriwijaya. Vol. 1(2), Hal: 4-17.

Robbins, Stephen P. 2009. Perilaku Organisasi: Organizational Behavior. Buku 1, Edisi 12. Jakarta: Salemba Empat.

Robbins, Stephen P. dan Coulter, Mary. 2012. Management. New Jersey: Pearson Education, Inc.

Sedarmayanti. 2013. Manajemen Sumber Daya Manusia. Bandung: Refika Aditama. Sugiyono. 2015. Metode Penelitian Pendidikan; Pendekatan Kuantitatif, Kualitatif dan $R \& D$. Bandung: Alfabeta. 